Canadian

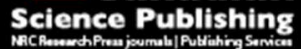

Canadian Journal of Forest Research Revue canadienne de recherche forestière

\title{
Influence of elevation and site productivity on conifer distributions across Alaskan temperate rainforests
}

\begin{tabular}{|r|l|}
\hline Journal: & Canadian Journal of Forest Research \\
\hline Manuscript ID & cjfr-2015-0283.R1 \\
\hline Danuscript Type: & Article \\
\hline Complete List of Authors: & $\begin{array}{l}\text { Caouette, John; The Nature Conservancy, } \\
\text { Steel, Ashley; Pacific Northwest Research Station, } \\
\text { Hennon, Paul; USDA Forest Service } \\
\text { Cunningham, Pat; Pacific Northwest Research Station, } \\
\text { Pohl, Catherine ; Catherine Pohl Biological Consulting } \\
\text { Schrader, Barbara; US Forest Service, Alaska Region }\end{array}$ \\
\hline Keyword: & landscape, elevation, biogeography, species distribution models, climate \\
\hline &
\end{tabular}

SCHOLARONE $^{\text {m }}$

Manuscripts 


\section{Influence of elevation and site productivity on conifer distributions across}

\section{Alaskan temperate rainforests}

3

4 J.P. Caouette ${ }^{1,2}$, E.A. Steel ${ }^{3}$, P.E. Hennon ${ }^{4,8}$, P.G. Cunningham ${ }^{5}$, C.A. Pohl ${ }^{6}$, B.A. Schrader ${ }^{7}$

$5 \quad{ }^{1}$ In memorium

$6 \quad 2$ The Nature Conservancy, 416 Harris Street \#301, Juneau, AK, USA

$7 \quad{ }^{3}$ Pacific Northwest Research Station, USDA Forest Service, 400 N 34th Street, Seattle, WA

898103, USA, Email asteel@fs.fed.us

$9{ }^{4}$ Pacific Northwest Research Station, USDA Forest Service, 11175 Auke Lake Way, Juneau, 10 AK, USA, Email phennon@fs.fed.us

$11{ }^{5}$ Pacific Northwest Research Station, USDA Forest Service, 3200 SW Jefferson Way, Corvallis, 12 OR, 97331, USA, Email pcunningham@fs.fed.us

$13{ }^{6}$ Catherine Pohl Biological Consulting, P.O. Box 21168, Juneau, AK, 99802, USA, Email

14 catherine.pohl@outlook.com

$15{ }^{7}$ Alaska Region, USDA Forest Service, 709 W $9^{\text {th }}$ Street, Juneau, AK, 99801, USA, Email

16 bschrader@fs.fed.us

$17{ }^{8}$ Corresponding Author: Paul Hennon, Forestry Sciences Laboratory, 11175 Auke Lake Way,

18 Juneau AK, 99801, USA, Email phennon@,fs.fed.us, Phone 907 586-8769, Fax 907 586-7848

19 Note: This study was initiated by the late John Caouette $(1964-2010)$ of The Nature

20 Conservancy. John's tireless efforts to synthesize and gather support for the idea; to find,

21 organize, and clean the data; and to provide early reports has been an inspiration to the

22 coworkers and collaborators he left behind. John's enthusiasm and drive for this project provided 
23 the coauthors of this report with the motivation to carry his work forward in the wake of his 24 untimely death in October, 2010. 


\section{Abstract:}

26 We investigated the influence of landscape factors on the distribution and life stage stability of

27 coastal tree species near the northern limit of their ranges. Using data from 1465 forest

28 inventory plots, we estimated probability of occurrence and basal area of six common conifer

29 species across three broad latitudinal regions of coastal Alaska. By also comparing models

30 across life stages of each species (seedlings, sapling, mature, and dead trees), we explored trends

31 in population stability at this leading edge of climate change. Elevation had a stronger influence

32 on the probability of tree species occurrence than on basal area; site productivity impacted both

33 estimated odds of presence and estimated basal area for most species in at least some regions.

34 Interestingly, there were fairly dramatic differences across species in the degree to which the 35 modeled probability of occurrence differed across the four life stages. Western redcedar, for 36 example, showed relatively stable distributions but other species appear to be in flux, e.g.,

37 yellow-cedar which has experienced widespread mortality at low elevations. Differential effects

38 of elevation on live versus dead basal area suggest mountain hemlock and yellow-cedar are

39 shifting upslope in some regions and that Sitka spruce is shifting downslope in the Northwest 40 region.

41 Key Words: landscape, elevation, species distribution models, climate, biogeography 


\section{Introduction}

44 Conifer forests in coastal Alaska at the current northern extent of temperate rainforests in North

45 America are experiencing a variety of landscape-scale pressures related to global climate change,

46 expanding human development, and increasing recreation demands (Haufler et al 2010).

47 Understanding resiliency of these forests in the face of these pressures is critical; yet, our

48 knowledge of landscape dynamics within these forests is limited. Emerging issues in this region

49 include maintaining ecosystem integrity, protecting cultural resources and values, and providing

50 functioning wildlife habitats, as well as identifying potential commodity uses of forestlands

51 (Oakes et al. 2015). An understanding of macro-scale physical and climatic predictors of species

52 distribution and productivity is essential for managing these unique and important forests.

53 Comparisons of realized species niches across life stages provide a first indication of whether

54 and in what ways species distributions may already be shifting. Such macro-scale models can

55 also provide a first step toward a more comprehensive modeling framework that might

56 eventually untangle mechanistic relationships at finer scales (Pearson and Dawson 2003).

57

58 Of the various resource management objectives that require detailed spatial information on tree

59 species, perhaps none is as compelling as understanding climate effects and how species are or

60 are not adapting to change. There is growing appreciation of how climate has shaped forests

61 historically, and concern for how existing forests will be impacted by a rapidly changing climate.

62 Because climate change is likely to affect each tree species in a unique manner, it is essential to

63 understand the distribution and habitat requirements of individual tree species in addition to

64 composite plant communities (Iverson et al. 2008, Woodall et al. 2009). Methods for predicting

65 future responses in forests, such as bioclimatic envelopes or climate profiles (e.g., Hamann and 
66 Wang 2006, Rehfeldt et al. 2006), are founded on current factors influencing the spatial

67 distributions of forest tree species.

69 Species distribution models (SDMs) are frequently used to predict occurrence and abundance of 70 organisms in landscapes where ground plot data are incomplete or where remote sensing cannot

71 adequately identify species. SDMs are used in forest management to estimate species ranges and

72 distributional limits, prioritize restoration and management activities, quantify available

73 resources in a particular area, or identify regions of active management, e.g., where species

74 diversity might be particularly high or where a native species might be particularly vulnerable to

75 competition from an invasive species (Peterson 2003). Models range in complexity from

76 bioclimatic envelopes that are typically constructed on the relationships between coarse species

77 distributions and climate variables to fine-scale species distribution models which may include

78 disturbances, soils, and other available information (Booth et al. 1988). Biotic factors such as

79 interspecies competition, herbivory, and pathogens are rarely explicitly included because of the

80 intricacy of interactions (Elith and Leathwick 2009); however these biotic factors are often

81 implicitly included via effects on plot data (Schroeder et al. 2010).

82

83 The coastal temperate rainforests of Alaska (Fig. 1) are largely intact ecosystems and offer an

84 ideal setting to explore natural processes driving the distribution and success of individual tree

85 species. These forests are relatively unique in western North America in that large areas have

86 had no previous logging history; fire is rare and has played a minimal role in contemporary forest

87 development in all but a few areas (Alaback 1988). While there has been considerable attention

88 to forests stressed by drought and other effects of climate change on the trailing edge of tree 
89 species ranges (Mátyás 2010), there is a need to study forests at the latitudinal and elevational

90 leading edge of range shifts. The six most common conifer species in the area reach the northern

91 extent of their respective natural ranges at particular latitudes in Southeast Alaska, or a location

92 to the northwest along the Gulf of Alaska (Fig. 1). Therefore, on-the-ground patterns reflect

93 natural processes driving species distribution and basal area growth at distributional extremes

94 where range shifts, potentially due to climate, are most likely to be detected.

95

96 Vegetation in this northernmost extent of the coastal temperate rainforest is still recovering and

97 migrating in response to the last glacial retreat millennia ago as well as responding to current effects of climate change (Peteet 1991). Responses to climate change and other disturbances can

99 include changes in occupancy of particular sites. Responses can also include changes in vigor, 100 growth rates, and density. Basal area, a commonly measured stand-level descriptor of forest 101 structure, can be considered an imperfect index of these types of responses (Cade 1997). We 102 note that occupancy and basal area reflect different ecological processes and likely respond to 103 different suites of environmental variables (Nielson et al. 2005). Conservation and management 104 of forested ecosystems responding to a changing climate rely on accurate descriptions of current 105 tree species distributions across large spatial extents, fine-scale estimates, and estimates of how 106 those geographic patterns may be changing over time. As a prime example, yellow-cedar has 107 experienced intense mortality in the region related to changes in snow cover with climate change 108 (Hennon et al. 2012). Broad-scale models involving life stages of each of the tree species can 109 help inform how their distributions may be changing. 
111 With changing climates, temperature can be a driving factor in determining treeline (Grace et al. 112 2002) and is a contributing factor at the trailing edge of species ranges (Mátyás 2010). Across

113 the coastal Alaskan temperate rain forest, tree species composition also appears to be controlled 114 at a finer scale by site productivity which is primarily related to soil drainage in this region 115 (Neiland 1971, Alaback 1982, Hennon et al. 1990). For example, shore pine is known to be 116 common in less productive wet, boggy soils; the cedars and mountain hemlock are most 117 competitive at intermediate drainage; and western hemlock and Sitka spruce dominate the most 118 productive, well drained sites. These tendencies as well as the mixed composition of most 119 forests are recognized in local plant association guides (e.g., DeMeo et al. 1992, Develice et al. 120 1999) but have not been interpreted across broad spatial extents in the context of latitude, 121 elevation, and climate change.

123 Acquiring empirical data on shifts in tree species distributions at the leading edge of climate 124 change is difficult. Accurate fine-scale data for many drivers of vegetation dynamics (e.g., 125 seasonal temperature extremes, water availability, and soils) are generally unavailable across the 126 range of coastal Alaskan landscapes. Fortunately, the USDA Forest Service's Forest Inventory 127 and Analysis program collects data from a large systematic sample of forested plots across the 128 region (Barrett and Christensen 2011). These data include species presence and absence, basal 129 area by species, number of seedlings and saplings (as judged from size class data) by species, 130 and a simple site productivity classification (productive versus unproductive soils). Elevation 131 data are also widely available. Elevation and site productivity are static and do not change over 132 time, at least not on time scales of management relevance. Changes in the relationships between 
133 trees and these static, landscape features are therefore potential descriptors of changes in realized 134 species distributions.

136 In this study, we take a simple, transparent, and easily comparable approach to quantifying

137 landscape-scale factors that influence tree species distributions across the temperate rainforests 138 of coastal Alaska. We address the following questions:

139 1) How is elevation, a stationary surrogate for climatic conditions, related to the distribution and basal area of six common coastal Alaskan tree species and does that relationship differ across three major geographic regions?

2) Does site productivity have an additional impact on either occupancy or basal area for the six tree species or across the three geographic regions?

3) By comparing models for live trees, dead trees, and regeneration, can we see a shift in the relationship of stationary factors to species distributions over time? Are there indications that some species' relationship to elevation may be changing?

148 We focused on only two stationary predictors of tree species occupancy and basal area over a 149 vast geographic area, elevation and site productivity. By modeling presence versus absence 150 independently of basal area, we distinguished between factors associated with these two distinct 151 life history stages: seedling establishment and tree growth. Independent models for each of six 152 species and across each of three geographic regions allowed explicit comparisons of the effects 153 of our two stationary predictors on multiple species and areas within the leading edge of climate 154 change. Independent models for different life stages of each tree species provided a quantitative 
155 estimate of how relationships between observed tree distributions and stationary landscape 156 conditions may be shifting.

\section{Methods}

159 Region

160 We segregated the coastal rainforest in Alaska into three regions (Fig. 1). Forests along the Gulf 161 of Alaska west to Kodiak Island were considered to be in the Northwest region. This region is 162 the coldest and has historically had the most snowfall. Weather stations here (station numbers 163509685 and 509941) report mean annual maximum temperatures from 1949-2012 of 6.0 and $1647.8^{\circ} \mathrm{C}$ and mean annual snowfall of 4702 and $5664 \mathrm{~mm}$. Forests on the upper panhandle were 165 classified as being in the Middle region. Weather stations in this region (station numbers $166503490,503695,504092$ ) report mean annual maximum temperatures of $8.8,9.1$, and $9.3^{\circ} \mathrm{C}$ and 167 mean annual snowfall of 3081, 2210, and $1892 \mathrm{~mm}$ from 1949-2012. Forests on the lower 168 panhandle were classified as being in the Southeast region. Weather stations in the Southeast 169 region (station numbers 509919, 504590, 502227) reported mean annual maximum temperatures 170 as high as 9.7 to $10.6^{\circ} \mathrm{C}$ and mean annual snowfall of only 572 to $1473 \mathrm{~mm}$ during the same time

171 period. The northern or northwest limits of tree species are known to extend differentially into 172 these regions.

174 Moderated by the Pacific Ocean that delivers year-round precipitation (Harris et al. 1974, 175 Alaback 1982), a hypermaritime climate has influenced forest structure and composition of 176 coastal Alaska. Terrain is mountainous and has had an active glacial history. These are conifer177 dominated ecosystems of low tree species diversity. We studied the six most abundant tree 
178 species, with western hemlock (Tsuga heterophylla (Raf.) Sarg.) as the most common species 179 and lesser amounts of Sitka spruce (Picea sitchensis (Bong.) Carr.), yellow-cedar (Callitropsis nootkatensis (D. Don) D.P. Little), western redcedar (Thuja plicata Donn ex D. Don), mountain

181 hemlock (Tsuga mertensiana (Bong.) Carr.), and shore pine (Pinus contorta Dougl. ex Loud. var 182 contorta). Other conifer tree species occur but are either less common or distributed around the 183 fringes of coastal Alaska.

\section{Vegetation data}

186 We used 1465 Forest Inventory and Analysis (FIA) vegetation plots in unmanaged stands: 376 in 187 Northwest Region, 388 in Middle Region, and 701 in Southeast Region. These did not include 188 plots identified as being in timber harvest areas, which were omitted to avoid direct effects of 189 forest management on species composition and existing basal area. Plots used were distributed 190 fairly well across all three broad geographic regions (Fig. 1). Any large geographic gaps without 191 plots were generally in a national park or in US Forest Service wilderness areas.

193 Live and dead standing trees greater than $12.7 \mathrm{~cm}$ (5 in) diameter were recorded from 0.017 ha 194 (1/24 ac) circular plots from 1995 to 2003 (Barrett and Christensen 2011). Saplings (2.5 to $195 \quad 12.7 \mathrm{~cm}$ diameter $)$ and seedlings $(<2.5 \mathrm{~cm}$ diameter but over $15 \mathrm{~cm}$ tall $)$ were recorded from 1960.0013 ha $(1 / 300 \mathrm{ac})$ nested microplots. Note that these are size class distinctions, and do not 197 necessarily reflect life stages. Designation of site productivity was made by evaluations of tree 198 heights and site index. Plots judged to have the ability to produce $1.4 \mathrm{~m}^{3} \mathrm{ha}^{-1}$ of wood or more 199 annually were labeled "productive" and those that did not meet this threshold were labelled 200 "unproductive" (USDA FS 1972). Individual plots that were designated with "mixed 
201 productivity" were omitted from analyses where productivity class was a bivariate independent 202 variable. Shore pine and another subspecies (lodgepole pine, P. contorta var latifolia Englm.) 203 are not distinguished in FIA data; however, shore pine is by far the more common and 204 widespread.

\section{Statistical analysis}

207 We built independent models of tree distribution and basal area as a function of landscape-scale 208 stationary predictors (elevation and site productivity) for each of the six primary tree species 209 listed above and across each of the three regions of coastal Alaska described above. This data210 partitioning approach enabled simple interpretation of results and comparisons across regions 211 and species despite extreme natural imbalances in design; some species are not present in some 212 regions. Because of the large number of zeros in the data and because the factors influencing 213 early seedling establishment (probability of presence) may be different from those influencing 214 later tree responses to climate (basal area where present), we modeled distribution and basal area 215 of each tree species separately using a two-step modeling process akin to a hurdle model. Hurdle 216 models have been successfully used on a wide range of problems (e.g., Steel et al. 2012). In the

217 first step, we built a logistic regression model to explain presence-absence patterns or 218 distribution of tree species. In the second step, we modeled basal area of each species.

220 To examine relationships between elevation and species distribution, we constructed logistic 221 models in which tree presence was a function of elevation. Coefficients from logistics models 222 were transformed for display to show the change in the odds of presence for a $100 \mathrm{~m}$ gain in 223 elevation. Models to predict basal area used a log-transformed response and a normal 
224 distribution. For these models, the raw regression coefficient is displayed which does not have a

225 simple ecological definition but can be interpreted as a general positive or negative change with

226 increasing elevation. To explore the effects of site productivity, we eliminated sites with mixed

227 productivity classification and refit the models. We then added an indicator variable of site

228 productivity (unproductive versus productive) to the above models and also an interaction term

229 (elevation: productivity). We note that the indicator variable denotes a change in site

230 classification from unproductive to productive. Again, coefficients for the logistic model are

231 transformed to display the change in odds when considering an unproductive versus a productive

232 site. Raw coefficients are displayed for the log linear model. To explore the third question of

233 indications that the relationship to elevation may be changing over time for some species, we

234 used additional information on presence and absence of seedlings, saplings, and dead trees in

235 each plot as well as basal area of dead trees in each plot. We created independent models of

236 presence-absence for live trees, dead trees, seedlings, and saplings as well as independent models

237 of $\log ($ basal area) for dead trees and live trees. Life stage models were built using the original

238 data set with all site productivity classes included.

239

240 Because of the large sample size and the exploratory nature of these analyses, we did not test for

241 significance in a formal manner. We instead compared parameter estimates and their associated

242 confidence intervals. Where confidence intervals overlapped with zero we note that the

243 relationship was indistinguishable from zero and where confidence intervals did not overlap with

244 zero we conclude that a relationship likely exists. Where confidence intervals failed to overlap

245 with each other or with zero, we conclude that observed relationships are different from one

246 another. 


\section{Results}

249 The presence of tree species in FIA plots in the three regions corresponded well to previously 250 published natural information on ranges of four of the species (Fig. 1). For example, inventory 251 plots detected western redcedar as being restricted to the Southeast region (it occurred on four 252 plots just north of this border), which marks its northern extent (Andersen 1953). Small

253 populations of shore pine and yellow-cedar are known to extend far into the Northwest region 254 (Peteet 1991, Hennon and Trummer 2001, respectively), however these species were not 255 detected in FIA plots included in our analyses in this region.

Relationship of elevation with distribution and basal area of six common Alaska tree species.

258 Looking across all FIA plots in a region, the patterns of occupancy as a function of elevation 259 differed across species and across regions (Fig. 2). The percentage of plots in which a particular 260 species was present varied dramatically with elevation for most species (Fig. 3).

262 Western hemlock, western redcedar, and shore pine were more likely to be present in plots at 263 lower elevations and absent in plots at higher elevations, in those regions where the species 264 occurred (Fig. 2). Mountain hemlock followed the opposite tendency. It was generally found at 265 higher elevations across all regions (Fig. 2, 3). Presence of Sitka spruce was unrelated to 266 elevation in the Middle and Southeast regions in our sample, suggesting that it was similarly 267 present across the elevation range. It was, however, more common at low elevations in the 268 Northwest region (Fig. 2). Basal area of each species (where present) did not vary by elevation 
269 (Fig. 4). The only exception was mountain hemlock in the Middle region where there was an 270 indication of greater basal area at higher elevations.

272 Model coefficients describe how either probability of species presence or basal area differs as a 273 function of elevation. They supported and quantified what we observed in Figures 2-4. Most 274 elevation coefficients were significantly different from zero when predicting presence-absence 275 (Fig. 5). For most species, the coefficient for the presence/absence model was negative, 276 indicating reduced odds of being present as elevation increases. The exception was mountain

277 hemlock which had a large positive coefficient for elevation in all regions; the odds of this 278 species being present in an FIA plot increased with elevation. In the middle region, for example,

279 we estimate that the odds of mountain hemlock presence nearly double for every increase in $280100 \mathrm{~m}$ of elevation over the observed range. Sitka spruce was the one species to show a dramatic 281 interaction with region. The transformed elevation coefficient was effectively one, indicating no 282 effect of elevation on the odds of presence in a particular FIA plot, for both the Middle and 283 Southeast regions but it was strongly negative in the Northwest region.

285 There were fewer strong relationships between elevation and basal area (where a species was

286 present)(Fig. 5). Western hemlock and mountain hemlock again had opposite relationships with 287 elevation; basal area of western hemlock was reduced as elevation increased and basal area of 288 mountain hemlock increased with increasing elevation, though model coefficients for the 289 Northwest region were indistinguishable from zero (Fig. 5). There was again an interaction 290 between elevation and region for Sitka spruce with a negative effect of elevation on basal area 
291 only in the Northwest region. There was an indication that basal area of western redcedar tends 292 to be lower at higher elevations.

Relationship of site productivity to distribution and basal area

295 When added to a model that already contains elevation, an indicator of site productivity

296 (unproductive versus productive) generally had additional explanatory power for both species

297 presence/absence and basal area (Fig. 6). The odds of western hemlock and Sitka spruce

298 presence were higher in productive areas. Other species were more likely to be present in

299 unproductive areas. The two cedar species, for example, showed a reduced probability of 300 presence on productive sites after accounting for the effect of elevation (Fig. 6).

302 Where species were present, site productivity classification also had a strong effect on basal area 303 for Sitka spruce and western hemlock; however, there were indications of regional differences in 304 how western hemlock responded to site productivity. There were also regional differences in 305 how yellow-cedar responded to site productivity with site productivity having a notable positive 306 relationship with basal area in the Middle region but not in the Southeast region. Western 307 redcedar basal area was positively correlated with site productivity in the one region where it 308 was present (Southeast region). There was no apparent effect of site productivity on basal area of 309 mountain hemlock or shore pine in any region though both species are frequently present on 310 unproductive sites (Table 1).

312 There were few noteworthy interactions between site productivity and elevation when predicting 313 species presence/absence. The only exceptions were yellow-cedar (in the Southeast and Middle 
314 regions), western redcedar (in the Southeast Region) and western hemlock (in the Northwest

315 region). In these cases, there was an indication that the effect of elevation differed across

316 productivity classes. For example, yellow-cedar presence had a strongly negative relationship

317 with elevation at unproductive sites in both the Southeast and Middle regions; at productive sites

318 there was a marginally negative relationship with elevation in the Middle region and a fairly

319 positive relationship with elevation in the Southeast region. Western redcedar presence

320 probability in the Southeast region and western hemlock presence probability in the Northwest

321 region were also more negatively associated with elevation at unproductive than at productive

322 sites. There were no significant interactions when predicting the logarithm of basal area. Due to

323 the limited number of coefficients that could be distinguished from zero, these results are not

324 displayed.

325

326 Stability in relationships with elevation across lifestages

327 Analysis of the relationships between elevation and presence of live trees, dead trees, saplings, 328 and seedlings for each species revealed patterns of distributional stability or change for the six

329 tree species (Fig. 7). The coefficient values can be interpreted as the change in the odds of a 330 species being present for every $100 \mathrm{~m}$ increase in elevation by live trees, dead trees, saplings, and 331 seedlings and for each species. Where the coefficients differ across lifestages, it is an indication 332 that the relationship of that species' distribution to elevation is shifting over time (Fig. 7).

333 Western hemlock had relatively similar relationships with elevation across life stages in the

334 Northwest and Southeast regions. In the Middle region, smaller trees were more likely to be 335 present at higher elevations than mature and dead trees. In the Southeast region, seedlings of 336 western hemlock were present at somewhat lower elevations than the other life stages. There 
337 was a trend for dead yellow-cedar to be found at lower elevation, and for live trees and saplings

338 and seedlings to be found at progressively higher elevation; the strongest negative relationship

339 with elevation was for the dead trees and the weakest for seedlings and saplings. Dead mountain

340 hemlock occurred at somewhat lower elevations than other lifestages in the Northwest region.

341 The odds of Sitka spruce and shore pine presence as a function of elevation indicated relative

342 stability for the four life stages, except that the odds of live Sitka spruce tree presence was

343 reduced at low elevations in the Northwest region (Fig. 7).

345 The relationship between basal area and elevation was not dramatically different for dead versus

346 live trees (where present) for most species and in most regions (Fig. 8). As for the presence-

347 absence models above, we compared the coefficients between live and dead tree basal area

348 within each species to assess whether the relationship of that species' productivity to elevation is

349 stable. As in figures 5 and 6, positive values for these coefficients indicate increasing basal area

350 with elevation for live or dead trees, conversely negative values suggest reduced basal area with

351 increasing elevation. The positive effect of elevation was dramatically stronger for live versus

352 dead basal area for mountain hemlock in both the middle and Southeast regions. Yellow-cedar,

353 in Southeast regions, had a slightly positive relationship with elevation for live trees yet there

354 was no effect of elevation on dead basal area. In interpreting these models, we recognize that

355 dead standing trees used in our analysis may remain standing for various lengths of time in

356 inventory plots according to tree species, elevation, and productivity class and therefore

357 differences in parameters estimated across life stages may reflect multiple processes in addition 358 to climate change. 


\section{Discussion}

361 Elevation was a strong predictor of the distribution of six common conifer tree species across the expanse of the coastal temperate rainforest in Alaska, an area at the leading edge of climate change. Elevation was, however, a better predictor of occurrence than of basal area. Our simple yet quantitative models of the current realized niche for each species agreed well with published qualitative descriptions of species occurrence across the region (e.g., Hultén 1968, Vierick and Little 2007). Nested within these broad trends, a fine-scale indicator of site productivity refined our predictions of occurrence for almost every species within all relevant regions. For some species and within some regions, site quality also had a significant effect on basal area. By comparing models across life-stages, we observed indications, for some species and in some regions, of changing relationships between species distributions and elevation that may be

371 indicative of a changing climate. Interestingly, for other species, we observed no indication of

372 shifting species distributions (Table 1). Our findings can be applied to gain insight into species

373 of particular interest, for example to understand changes in the distribution of yellow-cedar

374 which has been impacted across portions of the region throughout the $20^{\text {th }}$ century.

Biogeography and forest management at the leading edge

377 The broad spatial arrangement of tree species, especially at their northern or northwestern-most

378 range limits in Alaska, is probably a result of distinct adaptations to particular climate factors as 379 well as differing migration histories. Therefore, patterns at this leading edge provide a unique 380 opportunity to observe range shifts as a result of climate change and other disturbances. Each of 381 our six tree species has natural ranges that extend far south of Alaska along the Pacific Coast to 382 California (Burns and Honkala 1990). Moisture deficits, possibly combined with fire, may pose 
383 the greatest risk of potential range retractions at the trailing edge of climate change in California,

384 as none of these species is tolerant to drought or fire. However, precipitation is not typically

385 limiting at low elevation in the northern portions of these species' ranges. Here, climate may

386 influence the elevational patterns of these trees by affecting their reproductive success and

387 competitive ability more than by imposing heat or drought to exceed their physiological limits.

At this leading edge of the climate envelope, elevation was a clear surrogate for latitude. The occurrence of several tree species showed a strong association with elevation. Two of the three species (western redcedar and shore pine) that were most often found at lower elevation also

392 have natural ranges that did not extend far to the northwest into Alaska. The third species, Sitka 393 spruce which has the most extensive range, had a tendency to occur at low elevations, but this 394 pattern was only present in the most northerly region. Mountain hemlock was most common at 395 higher elevations in all three regions in Alaska. The weaker relationship between basal area and 396 elevation suggests that climate and other factors related to elevation do not substantially affect 397 tree growth, either number or size of stems, in the same way as they affect seedling initiation. 398 The greater basal area of mountain hemlock at higher elevation combined with the negative 399 coefficient for probability of presence on productive sites is consistent with the observation that 400 mountain hemlock is only competitive on low productivity sites at low elevations (Martin et al. 401 1995)

403 Given more detailed knowledge of range limits, and occurrence by elevation and productivity 404 class, various forest management strategies in coastal Alaska may be employed to favor tree 405 species on particular sites. However, adapting forest management practices at species range 
406 edges is in the early stages of development (Milad et al. 2013). With robust distribution models

407 of tree species focusing on patterns at the limits of current species ranges, forest management

408 strategies could be developed for favoring regeneration and competition of species at their

409 current northern or upper elevational limits. Conservation methods might be employed to protect

410 trees at these limits, but various harvesting strategies could also be used to encourage natural

411 regeneration or, in combination with artificial regeneration (planting), to enhance migration

412 (Pedlar et al. 2012). The role of natural disturbance such as windthrow, landslides, and glacial

413 rebound in favoring migration of tree species needs to be investigated and related to active forest

414 management. High resolution species distribution models and associated GIS layers will

415 undoubtedly be a foundation for developing conservation and management strategies. Our

416 results can serve as inputs to these models, estimating occurrence and abundance where there are

417 no on-the-ground data.

419 Fine-scale effects of site quality

420 Site quality or productive potential is tied closely to soil moisture, a function of climate, soils,

421 and micro-topography. Site quality therefore operates at a fine spatial scale, nested within

422 elevation and climate, to influence the distribution and abundance of tree species. Forest

423 productivity is positively correlated with soil moisture in many forests of the world where water

424 is often limiting (Gholz et al. 1990). The opposite relationship is found in coastal Alaska, where

425 there is abundant year-round precipitation and droughts are relatively rare (Stephens et al. 1969).

426 In coastal Alaska, bogs and other forested peatlands that have developed on gentle slopes or in

427 soils with restricted drainage support less live conifer biomass, more open canopy conditions,

428 and a unique and diverse composition of tree and understory species (Neiland 1971). The cedars, 
429 mountain hemlock, and particularly shore pine tolerate marginal sites with poor drainage but 430 cannot compete with the faster growing trees on the favorable drained soils (Ruth and Harris 431 1979). We found western hemlock, western redcedar, yellow-cedar, and Sitka spruce to have 432 higher basal area on productive than unproductive sites, which is consistent with previous 433 observations and plant classification schemes (Neiland 1971, DeMeo et al. 1992, Martin et al. 434 1995).

436 Reduced competition can also influence the tendency of particular species to occupy marginal 437 sites. Western hemlock, for example, appeared to expand its niche to less productive conditions 438 in the Northwest Region where western redcedar is absent and shore pine and yellow-cedar 439 populations are very limited. Sitka spruce extends even further west beyond the other species on 440 Kodiak and Afognak Islands where it has no competition with conifers in a leading and slowly 441 expanding range edge (Griggs 1934). Improved hydrologic and soils data could be used with

442 forest inventory data to refine our results on how conifers respond across the drainage gradient 443 from bog to upland forest beyond the simple productive-unproductive classes that we used here. 444 Implications for a species in decline

446 Yellow-cedar is known to have experienced an intense mortality focused on lower elevations in 447 Alaska (Hennon et al. 2012). In the warmest region of our study, we found that the relationship 448 between elevation and yellow-cedar occurrence differed substantially among life stages (i.e., 449 more dead trees at lower elevation, more regeneration at higher elevation), indicative of an 450 unstable, shifting distribution (Fig. 7). The latitudinal and elevational limits of the intensive 451 yellow-cedar death are considered to be controlled by snow accumulation with inadequate snow 
452 leading to fine root freezing injury during cold weather in late winter or early spring (Hennon et

453 al. 2012). Snowpack may also protect yellow-cedar regeneration from deer browse by keeping

454 deer populations in check (White et al. 2009), or simply by covering seedlings during the non-

455 growing season when deer feed on them. These snow effects could explain the more abundant

456 yellow-cedar seedlings that we detected at higher elevation.

457

458 Fine-scale site productivity is also important in controlling both the distribution of yellow-cedar

459 and the occurrence of its intensive mortality. We do not have a clear understanding of the all the

460 mechanisms that contribute to our finding of varying competitive abilities on sites that are

461 productive (well-drained soils) and unproductive (saturated soils). However, growth of the two

462 cedar species may be favored on saturated soils by having a unique adaptation for acquiring

463 nutrients there through cation mobilization of nitrate (D’Amore et al. 2009).

465 Our findings suggest that even lands designated for conservation status and not influenced by

466 activities such as road building or timber harvesting may be expected to have dynamic vegetation

467 alteration, as species experience shifting distributions, possibly initiated through climate change.

468 Some such protected areas impacted by yellow-cedar mortality are already expressing

469 successional changes as yellow-cedars are replaced by other species such as western hemlock

470 (Oakes et al. 2014). We note that caution should be used in attempting to interpret population

471 dynamics of long-lived tree species from forest plot data because of the possibility of longer-

472 term episodic reproduction or mortality (Lertzman 1995) and factors unrelated to climate that

473 can cause tree mortality. 
475

476

477

478

479

480

481

482

\section{Climate as a factor in future tree species distributions}

Shifts across life stages in the relationship between the distribution of particular tree species with respect to latitude and elevation may suggest population expansion or contraction in response to a changing climate. We observed indications of such shifts not only for yellow-cedar but also for mountain hemlock and Sitka spruce (Table 1) and similar results have been found by others. For example, by comparing the geographic distribution of seedlings and tree biomass from inventory plots in the eastern US, Woodall et al. (2009) found the mean latitude of seedlings to be $20 \mathrm{~km}$ north of tree biomass for northern species, but southern species appeared static. As in our study, results on life stages should be interpreted cautiously because seedlings and saplings represented size classes and not necessarily recent regeneration. Coldest mean temperature of the month, growing degree days, and moisture indices are useful in predicting vegetation ranges in northern Europe (Sykes and Prentice 1996) and western North America (Shafer et al. 2001). For coastal Alaska, we would add snow accumulation (or snowpack) as an important controlling climate factor of conifer occurrence and abundance.

The climate of coastal Alaska is expected to become warmer and slightly wetter in the next century (Wolken et al. 2011). Forest trees will experience warmer winters, longer growing seasons, and as the mean winter temperature warms above freezing, considerably reduced snow accumulation in some areas. The region is predicted to have the greatest loss of days below freezing of any area of North America in the $21^{\text {st }}$ century (Meehl, et al. 2004) because current winter mean temperatures hover close to the $0^{\circ} \mathrm{C}$ freezing threshold. Species reliant on snow for either greater competitive status (mountain hemlock) or for protection from direct weather injury (yellow-cedar) are likely to experience diminished suitable habitat. We found both of these 
498 species to be associated with higher elevations in Alaska, especially for mountain hemlock. Both 499 tree species have also been projected to lose habitat in British Columbia as other conifer species 500 from lower elevation would be expected to shift upward (Hamann and Wang 2006). Our study 501 found western hemlock, Sitka spruce, western redcedar, and shore pine to be associated with low 502 elevations in Alaska, and have extensive ranges to the south, suggesting that they may be favored 503 by the projected climate during the next century. These tree species may benefit directly by 504 warmer conditions but so could individual insects (e.g., spruce aphid, Powell and Parry 1976), 505 pathogens (e.g., dwarf mistletoe, Barrett et al. 2012), and herbivores (e.g., deer, White et al. 506 2009) to offset gains in productivity.

507

508 The current distributions of forest trees reflect the realized ecological niche of each species, the 509 culmination of their adaptation to environmental factors, competition with other tree species, 510 interaction with other biotic factors, and migration from historic distributions. Untangling these 511 complex interactions will be challenging; however, our quantification of their associations with 512 several stationary factors should form a basis for understanding edaphic and climate niche 513 requirements of coastal conifers. By comparing live versus dead tree basal area and occupancy 514 across multiple life stages, we revealed possible maladaptation to climate and possible 515 distribution contraction or expansion for some species and not others. Our results provide a 516 convenient glimpse of fluctuating populations across latitude, elevation, and site productivity.

517 Our analysis suggests instability of yellow-cedar, mountain hemlock, and Sitka spruce. Western 518 hemlock, western redcedar, and shore pine species appear to have more stable distributions

519 (Table 1). Each of our tree species are found in mixed-species communities but they are likely to 520 respond individually to climate change, as is suggested by the fossil record (Davis and Shaw 
521 2001). Our models of each independent tree species enable us to begin imagining how

522 communities across whole landscapes might shift and re-arrange under a changing climate.

523 


\section{Acknowledgments}

525 We wish to thank Tara Barrett and Ken Winterburger for guidance with forest inventory plot 526 data, Rob Develice and Robert Pattison for help in interpreting the northwest limits of tree

527 species, Melinda Lamb who produced the Figure 1 map, and Tara Barrett and Lauren Oakes who

528 made helpful suggestions on an early manuscript draft. We appreciate the financial assistance

529 from the USFS Region 10 Regional Office and oversight by The Nature Conservancy for their 530 support to John Caouette.

\section{$532 \quad$ Literature cited}

534 Alaback, P.B. 1982. Dynamics of understory biomass in Sitka spruce-western hemlock forests of 535 Southeast Alaska. Ecology. 63: 1932-1948.

536

537 Andersen, H.E. 1953. Range of western redcedar (Thuja plicata) in Alaska. U.S. Dep. Agric., 538 For. Serv., Juneau, AK. Technical Note No. 22. 2 p.

539

540 Barrett, T.M., and Christensen, G.A. 2011. Forests of southeast and south-central Alaska, 2004-

541 2008: five year forest inventory and analysis report. Gen. Tech. Rep. PNW-GTR-835. U.S. Dep.

542 Agric., Forest Service. Pacific Northwest Research Station. Portland, OR. 156 p.

544 Barrett, T.; Latta, G., Hennon, P., Eskelson, B.N.I., and Ternesgen, H. 2012. Modeling host545 parasite distributions under changing climate: Tsuga heterophylla and Arceuthobium tsugense in 546 Alaska. Can. J. For. Res. 42: 642-656. 
548 Booth, T.H., Nix, H.A., Hutchinson, M.F., and Jovanovic, T. 1988. Niche analysis and tree 549 species introduction. For. Ecol. Man. 23: 47-59.

550

551 Burns, R.M., and Honkala, B.H. 1990. Silvics of North America. Vol. 1, conifers. US. Dep. 552 Agric., Forest Service, Agriculture handbook 654. Washington, DC. 675p.

553

554 Cade, B.S. 1997. Comparison of tree basal area and canopy cover in habitat models: subalpine 555 forest. Journal of Wildlife Management 61: 326-336.

556

557 D’Amore, D.V., Hennon, P.E., Schaberg, P.G., and Hawley, G. 2009. Adaptation to exploit 558 nitrate in surface soils predisposes yellow-cedar to climate change-induced decline while 559 enhancing the survival of redcedar: a new hypothesis. Forest Ecology and Management. 258: $560 \quad 2261-2268$.

561

562 Davis, M. B., and Shaw, R. G. 2001. Range shifts and adaptive responses to Quaternary climate 563 change. Science 292: 673-679.

564

565 DeMeo, T., Martin, J., and West, R.A. 1992. Forest plant association management guide, 566 Ketchikan Area, Tongass National Forest. U.S. Dep. Agric., For. Serv. Alaska Region, Juneau, 567 AK. R10-MB-210. 405p. 
569 DeVelice, R.L., Hubbard, C.J., Boggs, K., Boudreau, S., Potkin, M., Boucher, T., and Wertheim,

570 C. 1999. Plant community types of the Chugach National Forest: southcentral Alaska. USDA

571 Forest Service, Chugach National Forest, Alaska Region Technical Publication R10-TP-76.

572 Anchorage, AK. 375 p.

573

574 Elith, J., and Leathwick, J.R. 2009. Species distribution models: ecological explanation and

575 predictions across space and time. Ann. Rev. Ecol. Syst. 40: 677-697.

576

577 Grace, J., Berninger, F., and Nagy, L. 2002. Impacts of climate change on the tree line. Annals of 578 Botany. 90: 537-544.

579

580 Griffin, J.R., and Critchfield, W.B. 1972. The distribution of forest trees in California. USDA

581 For. Serv., Pacific Southwest forest and range experiment station, Berkeley, CA. Research Paper 582 PSW-82. $114 \mathrm{p}$.

583

584 Griggs, R.F. 1934. The edge of the forest in Alaska and the reasons for its position. Ecology. 15: $58580-96$.

586

587 Hamann, A., and Wang, T. 2006. Potential effects of climate change on ecosystem and tree 588 species distribution in British Columbia. Ecology. 87: 2773-2786. 
590 Harris, A.S., Hutchison, O.K., Meehan, W.R., Swanston, D.N., Helmers, A.E., Hendee, J.C., and 591 Collins, T.M. 1974. The Forest Ecosystem of Southeast Alaska 1. The Setting. General 592 Technical Report PNW-GTR-12. USDA Forest Service, Juneau, AK.

593

594 Haufler, J.B., C.A. Mehl, and S. Yeats. 2010. Climate change: anticipated effects on ecosystem 595 services and potential actions by the Alaska Region, U.S. Forest Service. Ecosystem

596 Management Research Institute, Seeley Lake, Montana, USA.

597

598 Hennon, P.E., D’Amore, D.V., Schaberg, P.G., Wittwer, D.T., and Shanley, C.S. 2012. Shifting

599 climate, altered niche, and a dynamic conservation strategy for yellow-cedar in the North Pacific 600 coastal rainforest. BioScience. 63: 147-158.

601

602 Hennon, P.E., Hansen, E.M., and Shaw, C.G. III. 1990. Dynamics of decline and mortality of 603 Chamaecyparis nootkatensis in southeast Alaska. Can. J. Bot. 68: 651-662.

604

605 Hennon, P.E., and Trummer, L.M. 2001. Yellow-cedar (Chamaecyparis nootkatensis) at the 606 northwest limits of its range in Prince William Sound, Alaska. Northwest Science. 75: 61-72. 607

608 Hultén, E. 1968. Flora of Alaska and neighboring territories. Stanford Press. Stanford, CA. 1008 609 p.

610 
611 Iverson, L.R., Prasad, A.M., Mathews, S.N., and Peters. M. 2008. Estimating potential habitat for 612134 eastern US tree species under six climate scenarios. Forest Ecology and Management. 254:

$613 \quad 390-406$.

614

615 Lertzman, K.P. 1995. Forest dynamics, differential mortality and recruitment probabilities.

616 Journal of Vegetation Science. 6: 191-204.

617

618 Martin, J.R., Trull, S.J., Brady, W.W., West, R.A., and Downs, J.M. 1995. Forest plant

619 association management guide, Chatham Area, Tongass National Forest. U.S. Dep. Agric., For.

620 Serv. Alaska Region, Juneau, AK. R10-TP-57. 405p.

621

622 Mátyás, C. 2010. Forecasts needed for retreating forests. Nature. 464: 1271.

623

624 Meehl, G.H., Tebaldi, C., and Nychka, D. 2004. Changes in frost day simulations of $21^{\text {st }}$ century 625 climate. Climate dynamics. 12: 495-511.

626

627 Milad, M., Schaich, H., and Konold, W. 2013. How is adaptation to climate change reflected in 628 current practice of forest management and conservation? Biodiversity and conservation. 22:

629 1181-1202.

630

631 Neiland, B.J. 1971. The forest-bog complex in Southeast Alaska. Vegetatio. 22: 1-63.

632 
633 Nielson, S.E., Johnson, C.J., Heard, D.C., and Boyce, M.S. 2005. Can models of presence-

634 absence be used to scale abundance? Two case studies considering extremes in life history.

635 Ecography. 28: 197-208.

636

637 Oakes, L.E., Hennon, P.E., Ardoin, N.M., D’Amore, D.V., Ferguson, A.J., Steel, E.A., Wittwer, 638 D.T., and Lambin. E.F. 2015. Conservation in a social-ecological system experiencing climate639 induced tree mortality. Biological Conservation. In press.

640

641 Oakes, L., Hennon, P., O’Hara, K. and Dirzo, R. 2014. Long-term changes in a temperate forest 642 impacted by climate change. Ecosphere. 5(135): 1-28.

643

644 Powell, W., and Parry, W.H. 1976. Effects of temperature on overwintering populations of the 645 green spruce aphid Elatobium abietinum. Ann. Appl. Biol. 82: 209-219.

646

647 Pearson, R.G., and Dawson T.P. 2003. Predicting the impacts of climate change on the 648 distribution of species: are bioclimate envelope models useful? Global Ecology and 649 Biogeography. 12: 361-371.

650

651 Pedlar, J.H., McKenney, D.W., Audin I., Beardmore, T., Beaulieu, J., Iverson, L., O’Neill, G.A., 652 Winder, R.S., and Ste-Marie, C. 2012. Placing forestry in the assisted migration debate.

653 BioScience 62: 835-842.

654 
655 Peteet, D.M. 1991. Postglacial migration history of lodgepole pine near Yakutat, Alaska. Can. J.

656 Bot. 69: 786-796.

657

658 Peterson, A.T. 2003. Predicting the geography of species' invasions via ecological niche 659 modeling. Quarterly Review of Biology. 78: 419-433.

660

661 Rehfeldt, G.E., Crookston, N.L., Warwell, M.V., and Evans, J.S. 2006. Empirical analyses of 662 plant-climate relationships for the western United States. Int. J. Plant Sci. 167: 1123-1150.

663

664 Ruth, R.H., and Harris, A.S. 1979. Management of western hemlock-Sitka spruce forests for 665 timber production. U.S. Dep. Agric., For. Serv., Pacific Northwest Forest and Range Experiment 666 Station. Portland, OR. General Technical Report PNW-88. 197p.

667

668 Shafer, S.L., Bartlein, P.J., and Thompson, R.S. 2001. Potential changes in the distributions of 669 western North America tree and shrub taxa under future climate scenarios. Ecosystems. 4: 200$670 \quad 215$.

671

672 Schroeder, T.A., Hamann, A., Wang, T., and Coops, N.C. 2010. Occurrence and dominance of 673 six Pacific Northwest conifer species. Journal of Vegetation Science. 21: 586-596.

674

675 Steel, E.A., Jensen, D.W., Burnett, K.W., Christiansen, K., Firman, J.C., Feist, B.E., Anlauf, K., 676 and Larsen, D.P. 2012. Landscape characteristics and coho salmon (Oncorhynchus kisutch) 
677 distributions: explaining abundance versus occupancy. Canadian Journal of Fisheries and 678 Aquatic Sciences. 69: 457-468.

679

680 Stephens, F.R., Gass, C.R., Billings, R.F., and Paulson, D.E. 1969. Soils and associated

681 ecosystems of the Tongass. U.S. Department of Agriculture, Forest Service. Alaska Region

682 report. Juneau, AK. 139p.

683

684 Sykes, M.T., and Prentice, I.C. 1996. Climate change, tree species distributions and forest

685 dynamics: a case study in the mixed conifer/northern hardwoods zone of northern Europe.

686 Climate Change. 34: 161-177.

687

688

US Department of Agriculture, Forest Service. 1972. Forest survey handbook FSH 4809.11. US

689 Government Printing Office. Washington, DC. 279 p.

690

691 Vierick, L.A., Little, E.L. 2007. Alaska trees and shrubs. Second edition. University of Alaska

692 Press. Fairbanks, AK. 359 p.

693

694 White, K.S., Pendleton, G.W., and Hood. E. 2009. Effects of snow on Sitka black-tailed deer

695 browse availability and nutritional carrying capacity in southeastern Alaska. Journal of Wildlife

696 Management. 73: 481-487.

697

698 Wolken, J.M., Hollingsworth, T.N., Rupp, S.T., Chapin, F.S., Trainor, S.F., Barrett, T.M.,

699 Beever, E.A., Sullivan, P.F., McGuire, A.D., Euskirchen, E.S., Hennon, P.E., Beever, E.A., 
700 Conn, J.S., Crone, L.K., D’Amore, D.V., Fresco, F., Hanley, T.A., Kielland, K., Kruse, J.J., 701 Patterson, T., Schuur, E.A.G., Verbyla, D.L., and Yarie, J. 2011. Evidence and implications of 702 recent and projected climate change on Alaska's forest ecosystems. Ecosphere. 2(11): 1-35.

703

704 Woodall, C.W., Oswalt, C.M., Westfall, J.A., Perry, J.A., Perry, C.H., Nelson, M.D., and Finley, 705 A.O. 2009. An indicator of tree migration in forests of the eastern United States. Forest Ecology 706 and Management. 257: 1434-1444.

707

708 
Table 1. A summary of modeled tree distributions by species, region, and lifestage. The three regions are Northwest (NW), Middle (M), and Southeast (SE) as described in Figure 1. Note that regional presence is defined as presence in more than 5 plots within the region. Arrows describe parameters for which the $95 \%$ confidence intervals do not overlap zero. Grey indicates that the $95 \%$ confidence interval is extremely close to zero. The direction of the arrow indicates the effect of increasing elevation or of productive site classification. The effect of site productivity classification was assessed in models that already contained elevation. The effects of interactions are summarized simply as presence of a significant interaction between elevation and site productivity in models to predict presence / absence of the species (PA) or basal area. There were no significant interaction effects in models of basal area. Results of models describing the effects of elevation on probability of presence by lifestage were summarized by describing the lifestage that differed from the others. 
Figure Captions.

Figure 1. Map of coastal Alaska indicating the location of forest inventory and analysis (FIA) plots, north or northwestern limits for each of the main tree species, and the regions (Northwest, Middle and Southeast) used in our analysis.

Figure 2: Distribution of elevation (m) for plots in which each of six tree species was present versus absent, by region. Solid line indicates median value; boxes identify the center quartiles of the data; and whiskers designate one-and-a-half times the interquartile range. Presence data were not plotted for a particular region and species if there were fewer than 5 plots in which the species was present in that region. Regions are defined in Figure 1.

Figure 3. Percentage of sites with species present across $150 \mathrm{~m}$ elevation classes for each of the six common conifer species and each of the three regions. Regions are defined in Figure 1. TSHE $=$ western hemlock $;$ THPL $=$ western redcedar $;$ CANO = yellow-cedar; TSME $=$ mountain hemlock; PISI $=$ Sitka spruce; $\mathrm{PICO}=$ shore pine.

Figure 4: Basal area $\left(\mathrm{m}^{2} / \mathrm{ha}\right)$ by elevation $(\mathrm{m})$, across six species and three regions, for plots in which the species was present. Dashed lines describe a locally weighted scatterplot smoothing for visual inspection of trends. Data were not plotted for a particular region and species if there were fewer than 5 plots in which the species was present in that region. Regions are defined in Figure 1.

Figure 5: Effects of elevation on species presence / absence and on basal area where present. For presence / absence (a), transformed coefficients representing the change in odds of species 
presence for a 100m gain in elevation are presented. For basal area (b), coefficients describe the effect of a change in elevation on $\log ($ basal area) using a linear regression model assuming normal errors. $\mathrm{TSHE}=$ western hemlock; THPL $=$ western redcedar $; \mathrm{CANO}=$ yellow-cedar; TSME = mountain hemlock; PISI = Sitka spruce; $\mathrm{PICO}=$ shore pine. Whiskers describe $95 \%$ confidence intervals around each parameter estimate. Regions are defined in Figure 1.

Figure 6: Regression coefficients for productivity in regression models to describe (a) presence/absence using a logistic model and (b) $\log$ (basal area) using a linear regression model assuming normal errors. Regression coefficients for the logistic model are transformed to describe the change in odds of presence for a productive versus unproductive site. In both cases, the subset of plots classified as "mixed productivity" were not used in model building and productivity was added to a model that already contained log-transformed elevation. TSHE $=$ western hemlock; THPL $=$ western redcedar $; \mathrm{CANO}=$ yellow-cedar; TSME $=$ mountain hemlock; PISI = Sitka spruce; PICO = shore pine. Whiskers describe $95 \%$ confidence intervals around each parameter estimate. Regions are defined in Figure 1.

Figure 7: Transformed regression coefficients for elevation in logistic regression models to across lifestage and region. Transformed coefficients can be interpreted as the change in odds of presence for a $100 \mathrm{~m}$ increase in elevation. Lifestages are identified at the center of each bar as dead (DEAD), live (LIVE), sapling (SAPL) or seedling (SEED). Vertical grey lines visually differentiate the three regions. Whiskers represent $95 \%$ confidence intervals around the parameter estimate. Where confidence intervals appear to be absent, they are simply smaller than the size of life stage label. Regions are identified as in Figure 1. 
Figure 8: Regression coefficients for elevation in linear regression models assuming normal errors to describe log (basal area) across life stage and region. Life stages are identified at the center of each bar as dead (DEAD) versus live (LIVE). Vertical grey lines visually differentiate the three regions. Whiskers describe 95\% confidence intervals around each parameter estimate. Where confidence intervals appear to be absent, they are simply smaller than the size of life stage label. Regions are identified as in Figure 1. 


\begin{tabular}{|c|c|c|c|c|c|c|}
\hline & , & $=$ =man & 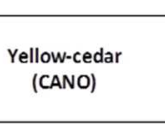 & minstritsen & sompow & s.ment \\
\hline & $\downarrow \downarrow$ & $\Downarrow$ & $\Downarrow$ & 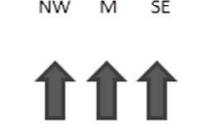 & $\Downarrow$ & 『 \\
\hline tem & $\Downarrow \Downarrow$ & $\Downarrow$ & $\Downarrow$ & $\boldsymbol{\mathbb { t } \boldsymbol { t }}$ & $\downarrow$ & \\
\hline \pm & $\boldsymbol{\Uparrow} \uparrow$ & $\Downarrow$ & $\Downarrow \Downarrow$ & $\Downarrow \downarrow$ & $\boldsymbol{\uparrow} \boldsymbol{t} \boldsymbol{t}$ & $\Downarrow$ \\
\hline 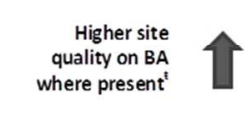 & $\boldsymbol{t} \boldsymbol{t}$ & $\boldsymbol{1}$ & $\boldsymbol{t}$ & & $\boldsymbol{\uparrow} \boldsymbol{t} \boldsymbol{t}$ & \\
\hline$=m$ & & & $\mathrm{PAPA}$ & & & \\
\hline 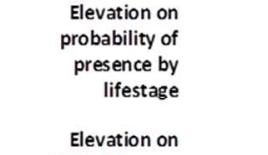 & & & & & 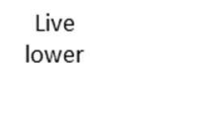 & \\
\hline
\end{tabular}

$254 \times 190 \mathrm{~mm}(96 \times 96 \mathrm{DPI})$ 


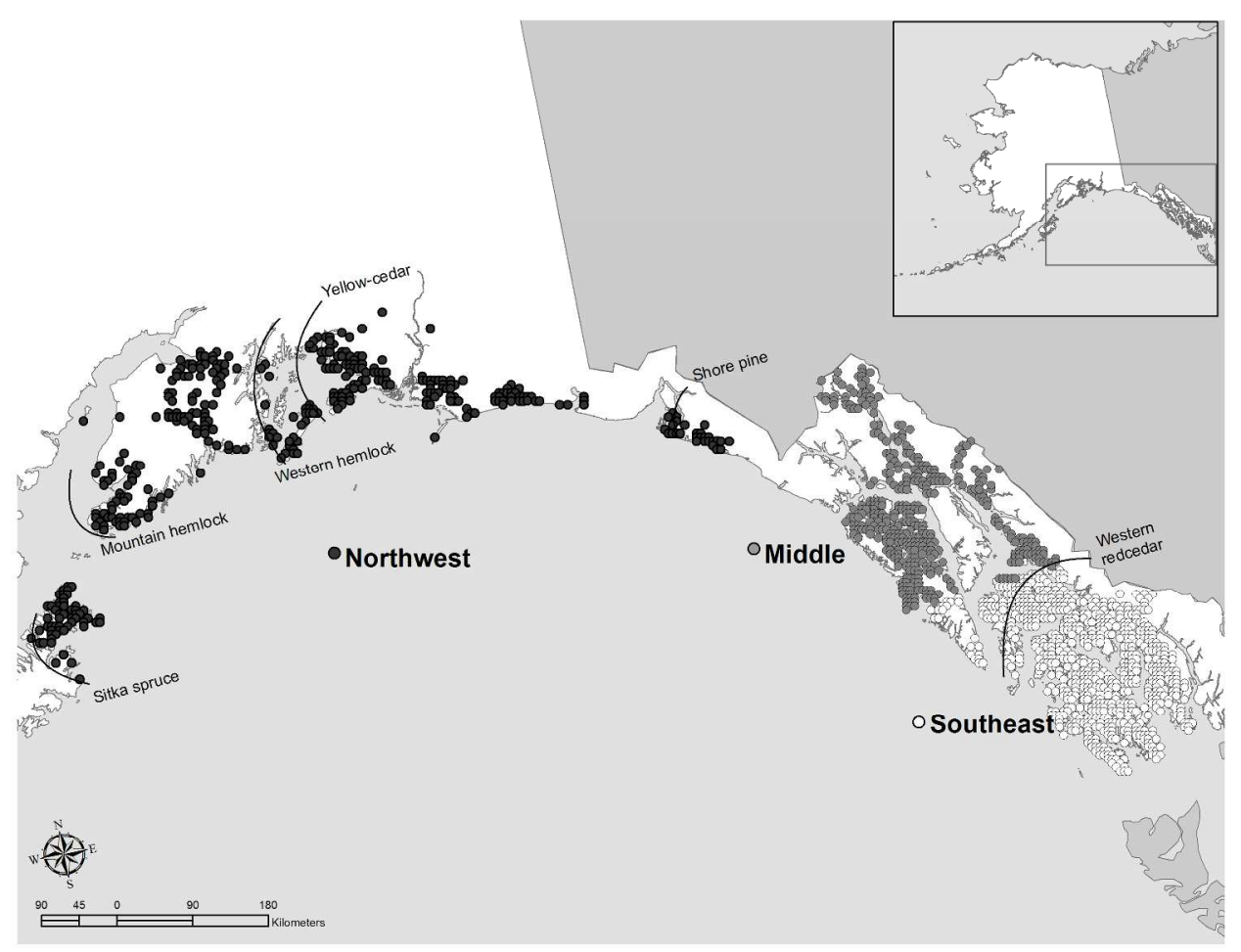

$279 \times 215 \mathrm{~mm}(300 \times 300 \mathrm{DPI})$ 

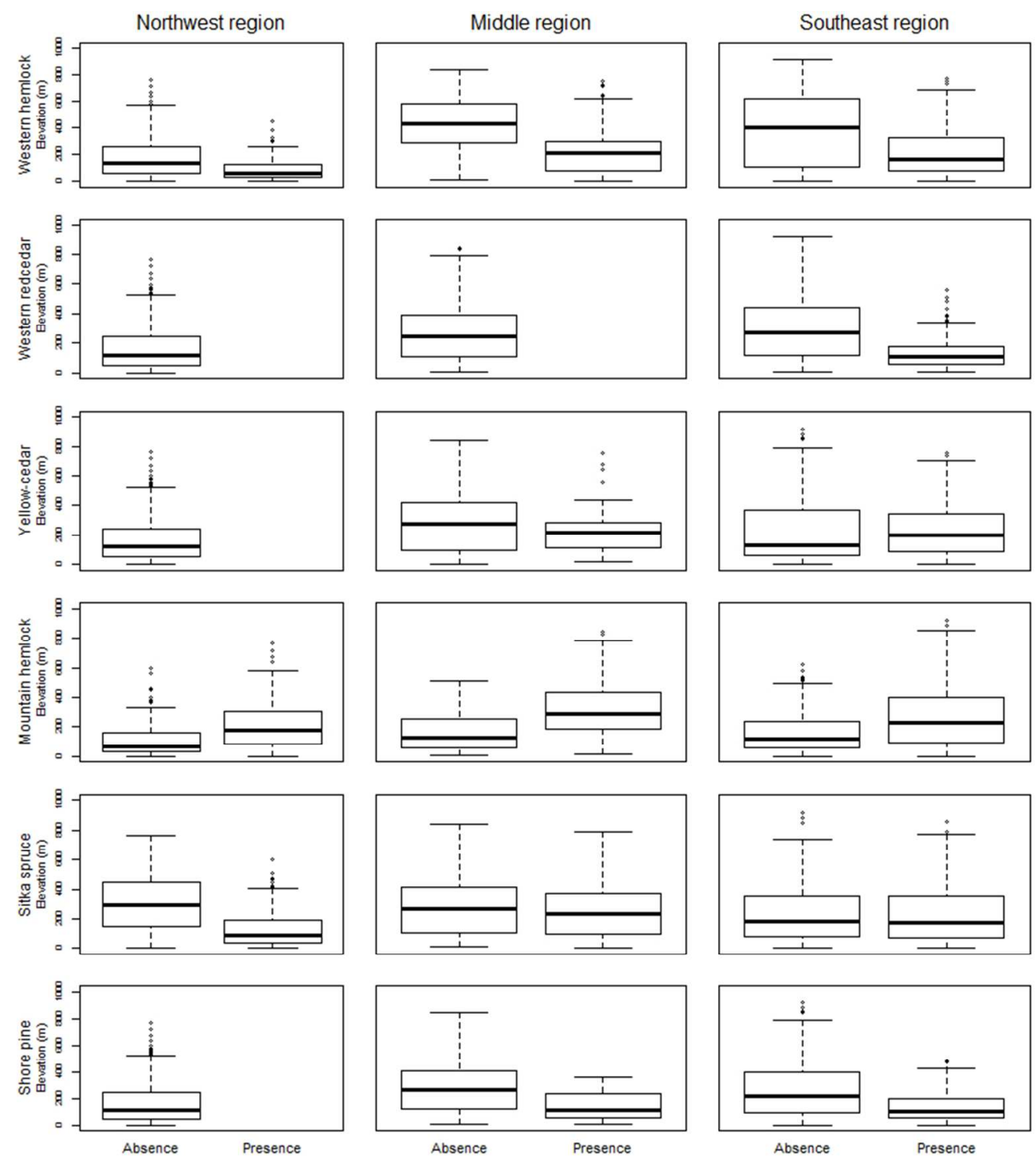

$287 \times 321 \mathrm{~mm}(72 \times 72$ DPI $)$ 


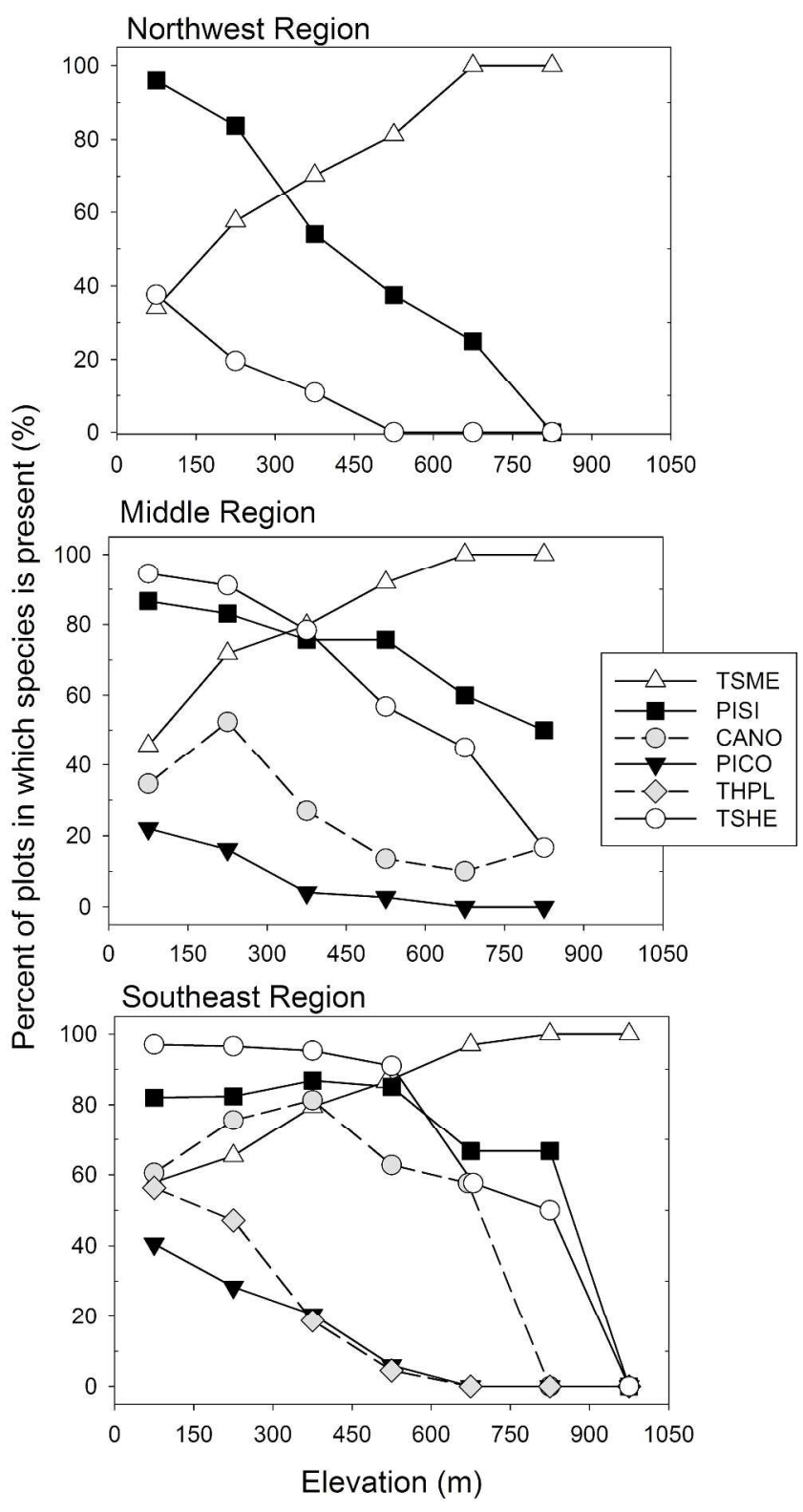

$272 \times 507 \mathrm{~mm}(300 \times 300 \mathrm{DPI})$ 

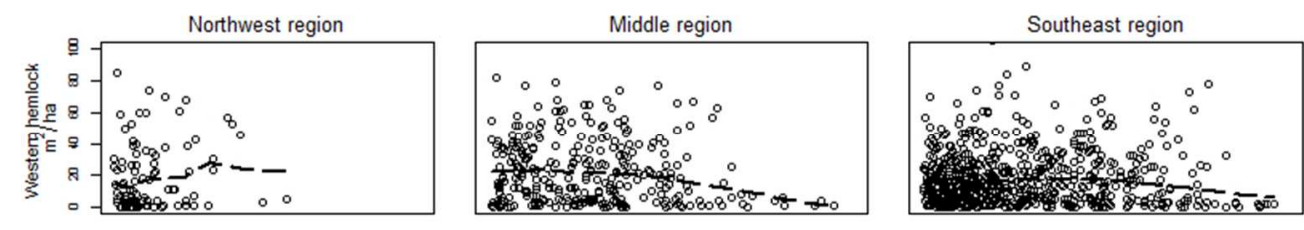

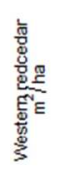
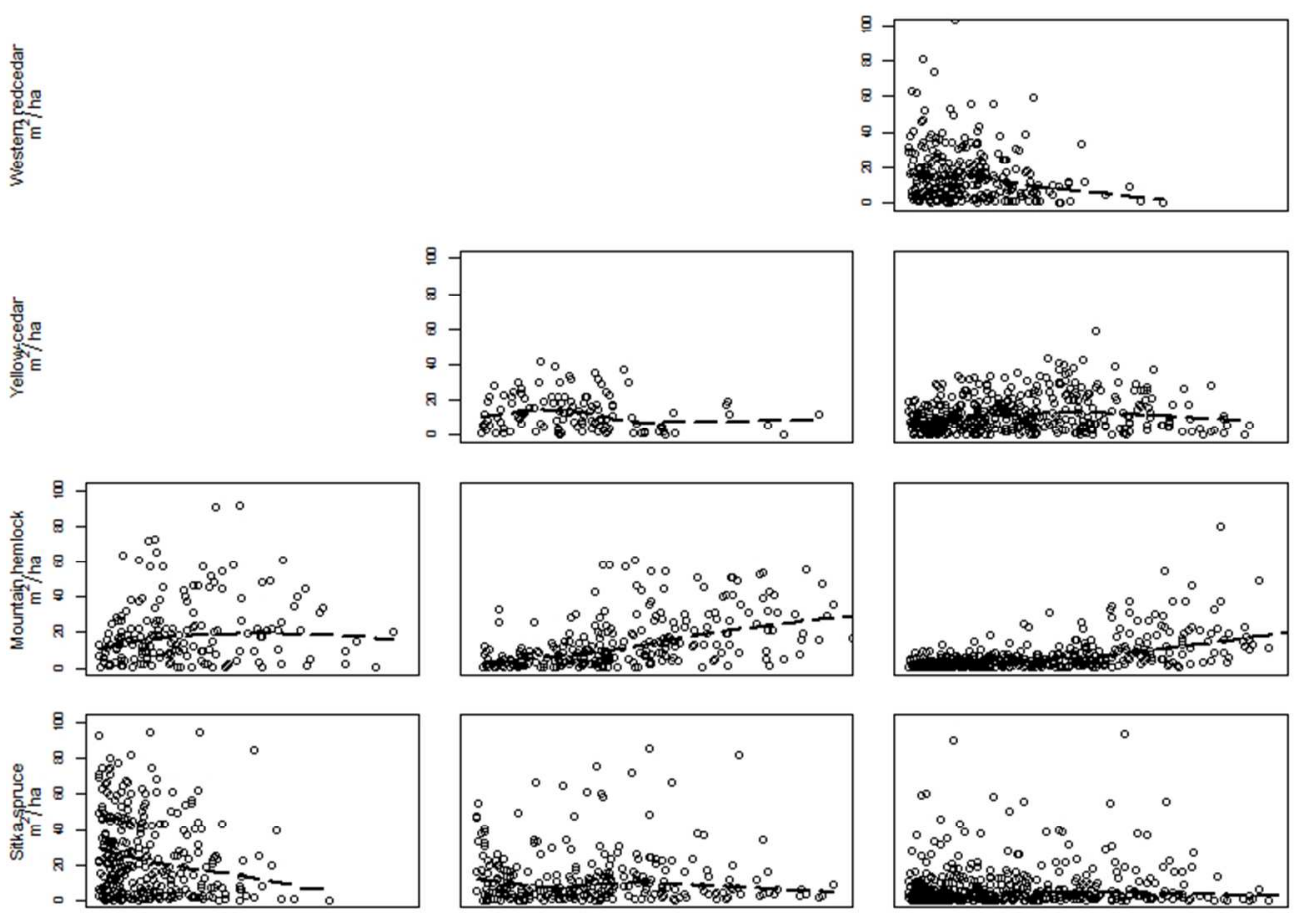

言焉
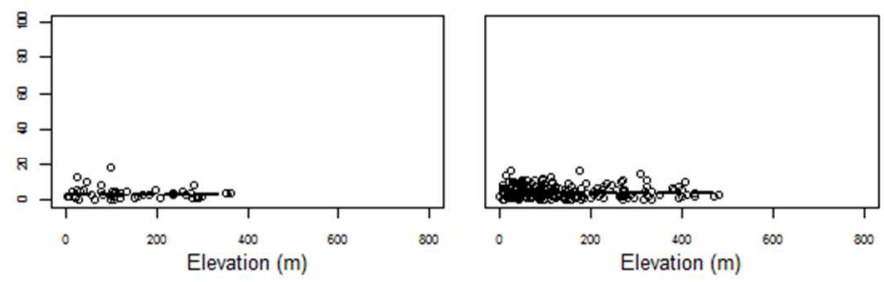

$287 \times 321 \mathrm{~mm}(72 \times 72$ DPI $)$ 

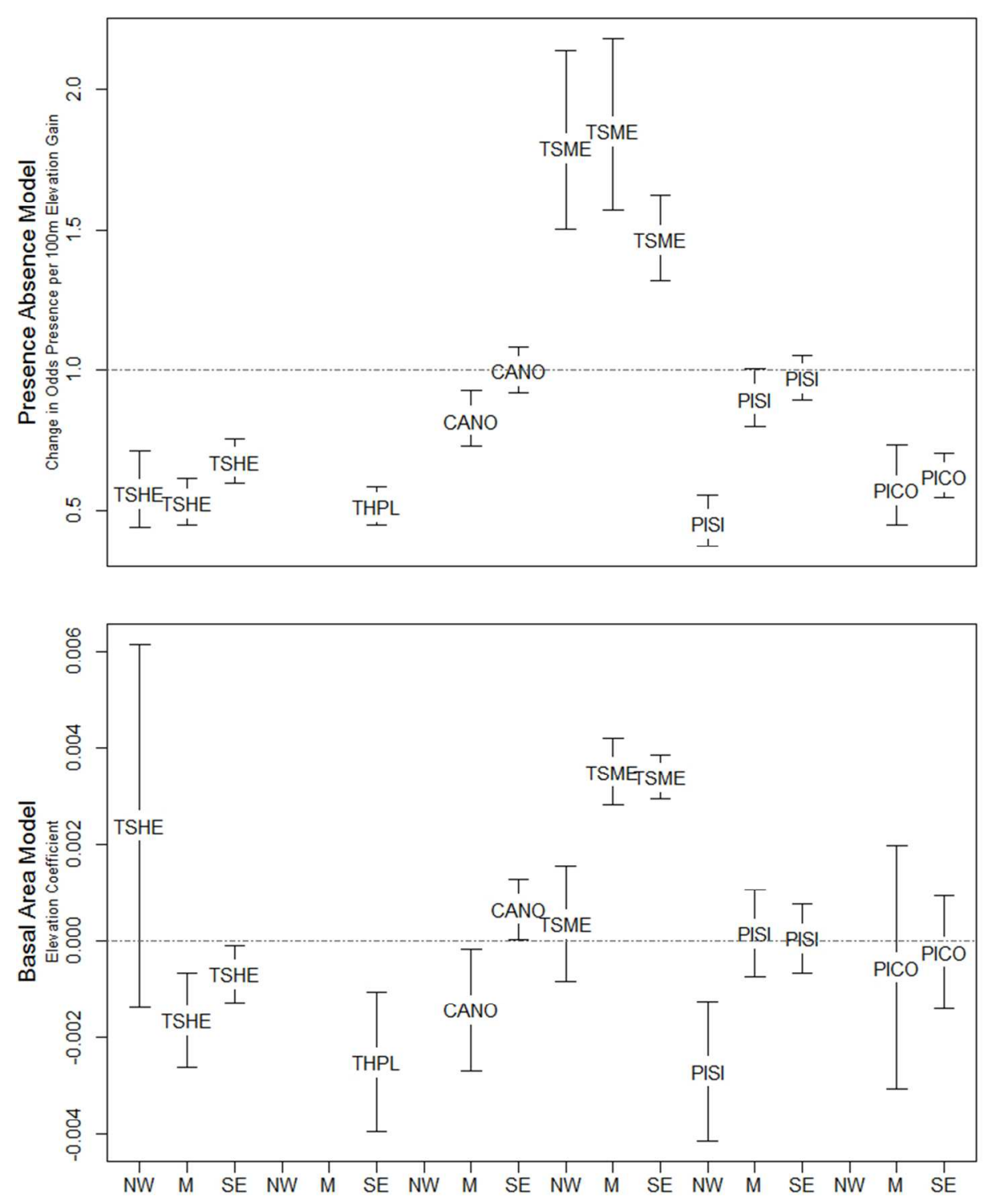

$291 \times 372 \mathrm{~mm}(72 \times 72 \mathrm{DPI})$ 

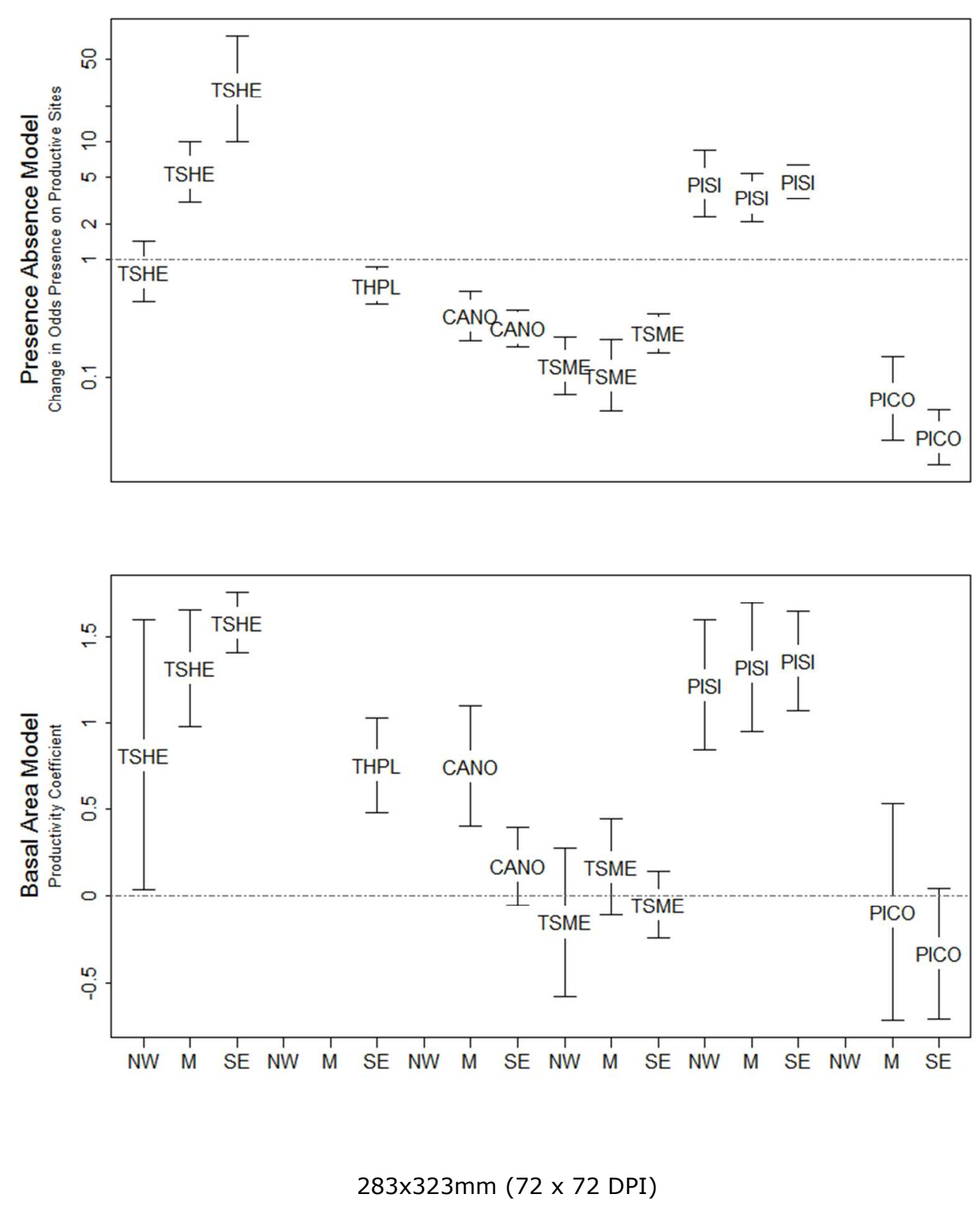

https://mc06.manuscriptcentral.com/cjfr-pubs 

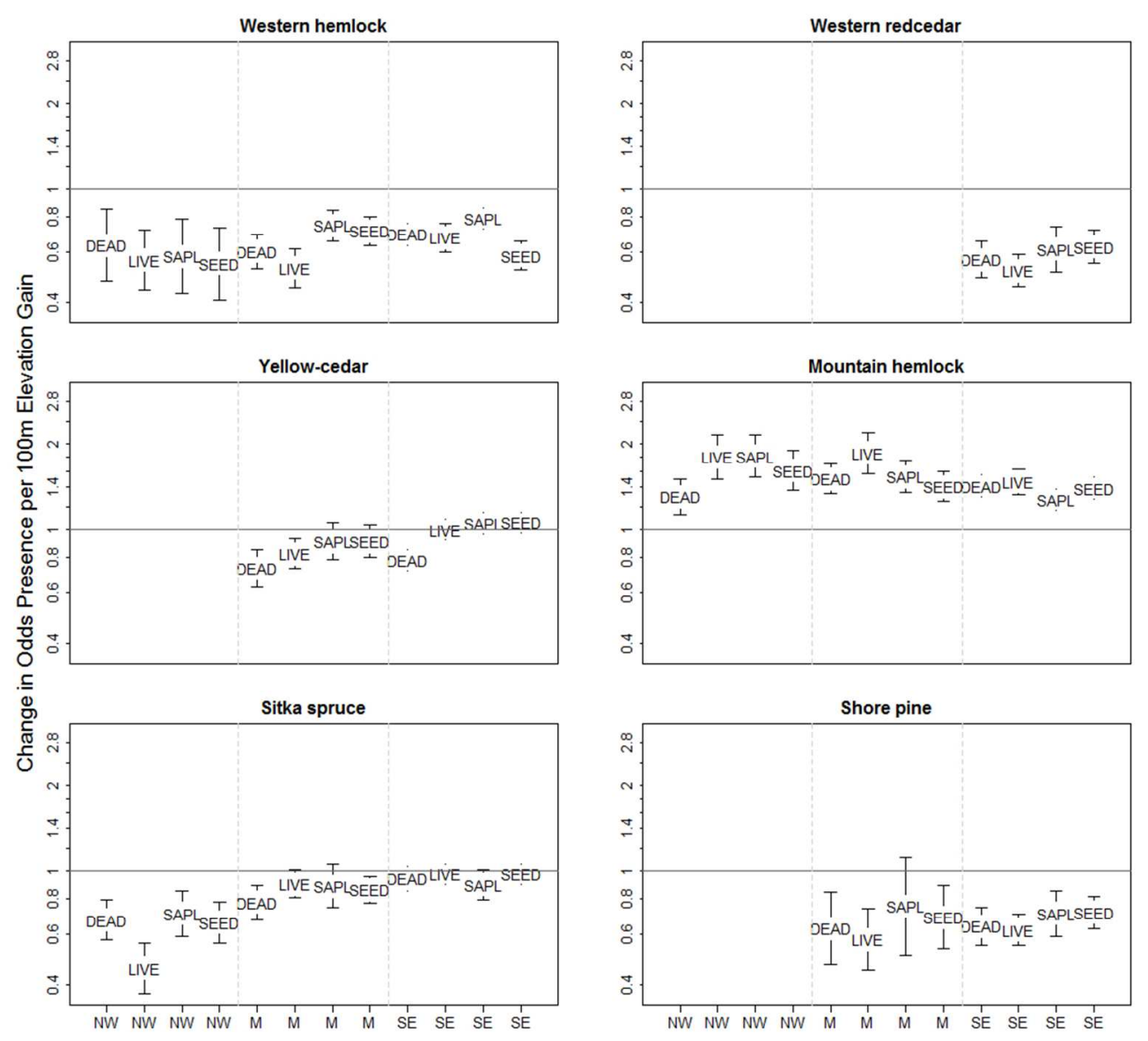

$363 \times 323 \mathrm{~mm}(72 \times 72 \mathrm{DPI})$ 

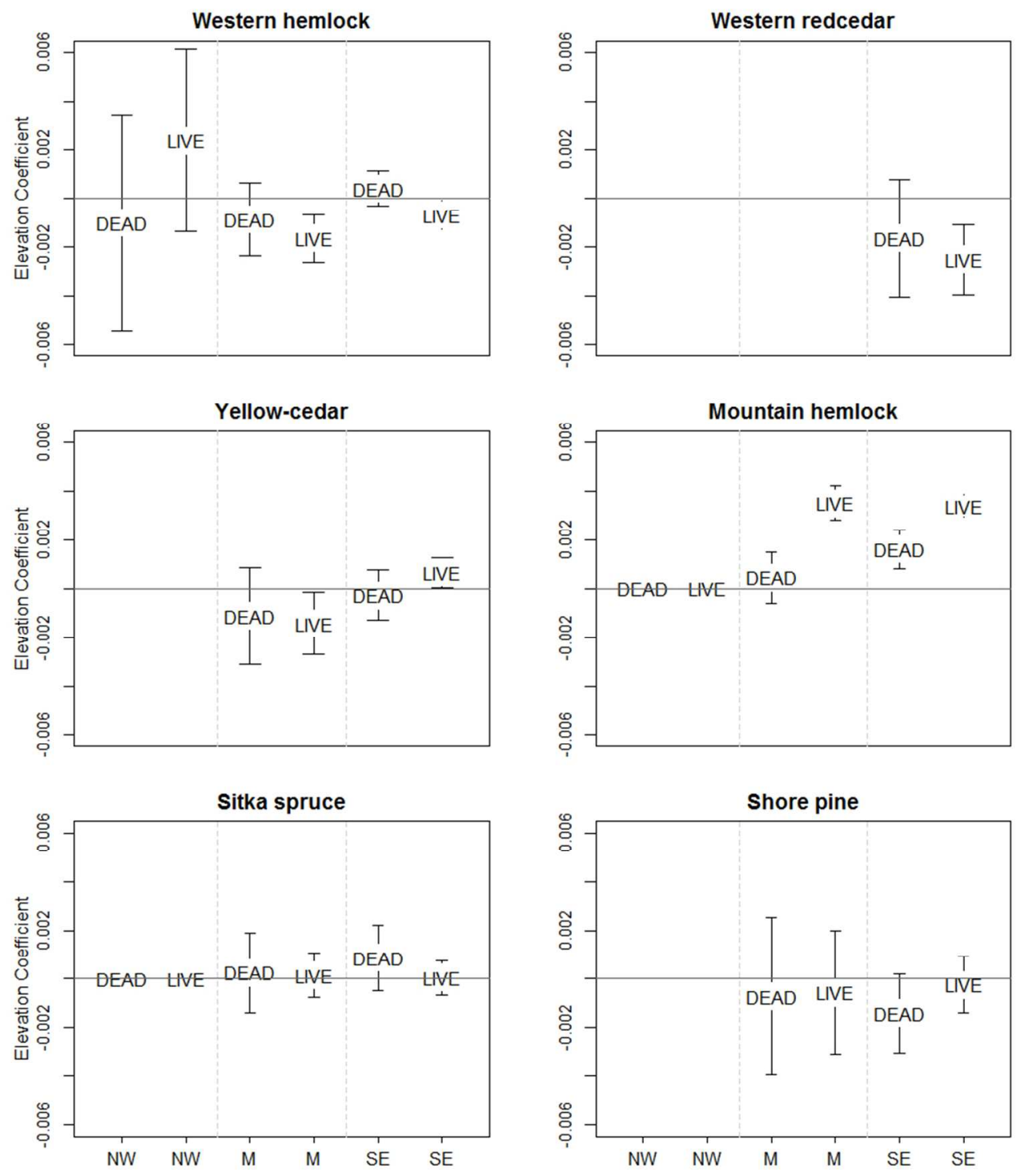

$331 \times 372 \mathrm{~mm}(72 \times 72 \mathrm{DPI})$ 